\title{
EDUCAÇÃO DO CAMPO E ESCOLA PÚBLICA: EXPERIÊNCIA E RESISTÊNCIA
}

\section{COUNTRYSIDE EDUCATION AND PUBLIC SCHOOL: EXPERIENCE AND RESISTANCE}

\author{
Maria Antônia de Souza ${ }^{1}$ \\ Rosana Aparecida da Cruz ${ }^{2}$
}

\begin{abstract}
RESUMO
Este trabalho objetiva analisar a escola pública tomando como referência os princípios da Educação do Campo e destacar experiências de resistência à concepção hegemônica de sociedade e de educação. Ele é fruto de pesquisa documental e colaborativa com professores e equipes pedagógicas de um município da Região Metropolitana de Curitiba. Do ponto de vista teórico-metodológico, o trabalho vincula-se aos estudos de natureza materialista histórico-dialética. Analisa a escola pública tomando como referência a constatação da presença das marcas tradicionais nas políticas e práticas pedagógicas. Evidenciam-se os fatores de resistência e experiências coletivas na construção da escola, de fato, pública e vinculada à classe trabalhadora. Demonstra que as experiências acontecem em meio a disputas político-pedagógicas e de projetos de sociedade.
\end{abstract}

Palavras-chave: Educação do Campo; Escola Pública; Disputa Político-Pedagógica

\begin{abstract}
This work aims to analyze the public school, taking as reference the principles of countryside education and highlighting experiences and resistance to the hegemonic conception of society and education. It is the result of documentary and collaborative research with teachers and pedagogical teams from a municipality in the Metropolitan Region of Curitiba. From a theoretical-methodological standpoint, the work is linked to studies of a dialectical materialistic. The public school is analyzed by taking as reference the observation of the presence of traditional brands in the pedagogical policies and practices. The factors of resistance and collective experiences in the construction of the school, in fact, public and linked to the working class are evidenced. It shows that the experiences happen amid political-pedagogical disputes and of society projects.
\end{abstract}

Keywords: Countryside Education; Public School; Pedagogical and Political Contest

\footnotetext{
1 Doutora em Educação pela Universidade Estadual de Campinas (1999). Mestre em Educação pela Universidade Estadual de Campinas (1994). Graduada em Geografia pela Universidade Estadual Paulista Júlio de Mesquita Filho (1991) e Graduada em Direito Universidade Tuiuti do Paraná (2012). Professora Associada da Universidade Estadual de Ponta Grossa e coordenadora do Grupo de Pesquisa Movimentos Sociais, Educação do Campo e Práticas Pedagógicas.

${ }^{2}$ Doutoranda em Educação pela Universidade Tuiuti do Paraná (2015). Mestre em Educação pela Universidade Tuiuti do Paraná (2014). Graduada em Pedagogia pela Universidade Católica do Paraná (1990). Desenvolve pesquisa sobre educação do campo, movimentos sociais do campo, políticas e práticas pedagógicas nas escolas localizadas no campo
} 


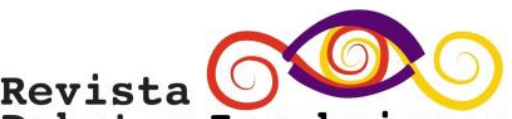 \\ Debates Insubmissos}

\section{INTRODUÇÃO}

O propósito deste artigo é analisar a escola pública rural tendo como referência os princípios da Educação do Campo e, ao mesmo tempo, destacar as experiências de resistência à concepção hegemônica de sociedade e de educação. Os princípios da Educação do Campo estão explícitos nos documentos nacionais como Diretrizes e Decreto Presidencial, bem como nas produções bibliográficas de pesquisadores e coletivos de Educação do Campo.

O artigo é fruto de investigações desenvolvidas junto ao Núcleo de Pesquisa em Educação do Campo, Movimentos Sociais e Práticas Pedagógicas (NUPECAMP), da Universidade Tuiuti do Paraná, e das ações político-pedagógicas realizadas em Tijucas do Sul. O município de Tijucas do Sul é um dos 29 municípios integrantes da Região Metropolitana de Curitiba (RMC). Conforme dados do IPARDES (2017), a extensão territorial municipal é de $671,930 \mathrm{Km}^{2}$, a densidade demográfica é de 23,18 hab./ Km², possui 0,636 de Índice de Desenvolvimento Humano, com população censitária de 14.537 habitantes, sendo 12.252 moradores do campo e 2.285 moradores da cidade. Para 2017, o IPARDES registra a estimativa de 16.161 habitantes no município. O número de escolas existentes na rede municipal é de 15 instituições, sendo 13 delas localizadas no campo. Dessas 15 instituições, 10 são escolas de Ensino Fundamental e cinco são Centros Municipais de Educação Infantil. Há dois colégios estaduais do campo, que ofertam de $6^{\circ}$ ao $9^{\circ}$ anos e Educação de Jovens e Adultos.

Mediante pesquisa documental foram analisados projetos político-pedagógicos, relatórios de reuniões com professores e equipe pedagógica, seminários de Educação do Campo no município, diários de campo, atas do Conselho Municipal de Educação, Plano Municipal de Educação e cartas / manifesto do Movimento Nacional de Educação do Campo. Esses documentos foram escolhidos por serem representativos das relações que se passam no espaço local no que diz respeito à problematização da política educacional voltada para a escola localizada no campo. E, nacionalmente, as diretrizes, o decreto presidencial 7.352 e as cartas/manifestos foram selecionados porque dispõem sobre os princípios da Educação do Campo. Dessa forma, foi possível identificar as marcas da escola pública rural, as marcas da ruralidade no município e as possibilidades de construir novas referências para as escolas públicas que ainda não possuem a identidade político-pedagógica vinculada à concepção da Educação do Campo.

Somou-se à pesquisa documental, o trabalho colaborativo com os professores, equipes pedagógicas e associações de moradores do campo. Durante sete anos foram realizados encontros para discutir os documentos nacionais da Educação do Campo, problematizar as características municipais no que tange ao trabalho no campo e interrogar políticas e práticas pedagógicas. Nesse período foram 


\section{Revista $\bigcirc \bigcirc$ \\ Debates Insubmissos}

reestruturados todos os projetos político-pedagógicos das escolas rurais do município de Tijucas do Sul, na tentativa de construir a identidade da escola no e do campo, conforme explícito em Caldart (2008; 2009), no decreto presidencial 7.352 de 2010 e nas diretrizes da Educação do Campo do estado do Paraná de 2006. Para que a escola seja considerada do campo, não basta estar localizada na área rural. É fundamental que ela tenha vínculo com os povos do campo, com as comunidades rurais, com os movimentos e organizações sociais. É esse vínculo que expressa a identidade da escola do campo.

No referido município, professores e equipes pedagógicas desconheciam a história da Educação do Campo. Os primeiros estudos foram vinculados ao curso de Pedagogia realizado na Universidade Tuiuti do Paraná (UTP), por uma diretora de escola pública, que cursou a disciplina Educação do Campo e defendeu monografia voltada à compreensão da identidade dos povos do campo e possibilidades de interferências na prática pedagógica. A pesquisa dessa diretora resultou na organização de estudos na escola e no envolvimento do município em um projeto de pesquisa financiado pela CAPES/Observatório da Educação no período de 2011 a 2014. O projeto foi realizado em rede pelas Universidades Federal de Santa Catarina (UFSC); Federal de Pelotas (UFPel) e UTP. Foi um estudo realizado na Região Sul do Brasil, com escolha de cinco municípios em cada um dos estados para realização do trabalho de campo. Os municípios escolhidos foram os de menor Índice de Desenvolvimento da Educação Básica. Tijucas do Sul era o município que possuía a escola de menor IDEB no estado do Paraná e, portanto, passou a integrar o conjunto de municípios que se vincularam ao projeto em rede. Importante realizar essa contextualização porque projetos como o Observatório da Educação são fundamentais para o fortalecimento de processos de formação continuada diretamente nas escolas públicas, e com possibilidade de bolsa de estudos para os professores da Educação Básica. Ele foi um dos desencadeadores das experiências e enfrentamentos político-pedagógicos tratados neste artigo, que, de certo modo, colocou a Educação do Campo em evidência na esfera municipal.

Do ponto de vista da pesquisa colaborativa, formado o grupo de estudos na escola, a primeira tarefa foi agir junto às comunidades e identificar a ruralidade municipal. $\mathrm{O}$ coletivo identificou em torno de 60 comunidades rurais que trabalham no campo como agricultores familiares, trabalhadores domésticos em chácaras, moradores do campo e assalariados nas cidades vizinhas. Também, a partir da investigação colaborativa foram identificadas a produção orgânica e a convencional nas pequenas propriedades, bem como atividades não-agrícolas como turismo rural e produtos artesanais. $\mathrm{O}$ estudo que teve início em uma escola, rapidamente foi estendido para todas as escolas municipais, em uma conjuntura política de apoio da Secretaria de Educação à formação continuada em Educação do Campo. Aos poucos, o trabalho coletivo foi ampliado para outros municípios mediante a realização 


\section{Revista (1) (O) \\ Debates Insubmissos}

dos Seminários Intermunicipais de Educação do Campo, cuja primeira edição realizou-se em Tijucas do Sul no ano de 2014.

Em seguida, a tarefa foi a de problematizar os projetos político-pedagógicos, até então distanciados das comunidades rurais e reproduzidos de uma escola para outra; e discutir práticas pedagógicas e materiais didáticos à luz dos princípios da Educação do Campo, das diretrizes nacionais (BRASIL, 2002; 2008; 2010), e das diretrizes estaduais da Educação do Campo (PARANÁ, 2006). Por fim, os estudos sobre os textos de coletivos e de pesquisadores da Educação do Campo, a exemplo de Arroyo (2010); Caldart (2004, 2008, 2009); Fernandes (2004, 2012), Molina e Sá (2012), Munarim (2008, 2010, 2011), Ribeiro (2012) e Souza $(2008,2011)$. Estudos que permitiram a compreensão da trajetória da Educação e dos seus princípios vinculados a outro projeto de campo (da agricultura camponesa familiar) e de educação em perspectiva transformadora e dialógica segundo a concepção de Freire (1987).

Todas as ações foram registradas em diário de campo e, posteriormente, foram objeto de investigação de professores do município, que trabalham nas escolas localizadas no campo, a exemplo da dissertação de Cruz (2014) e Machado (2016), bem como a tese de Cruz (2018).

A análise das ações desencadeadas no município e dos documentos foi pautada, teoricamente, pelo materialismo histórico dialético. O trabalho colaborativo teve como ponto de partida as condições objetivas das escolas e da política local, bem como as determinações externas no campo da política educacional. A análise documental foi pautada pela evidenciação da força exercida pelos intelectuais orgânicos e coletivos na construção da concepção de Educação do Campo.

As construções teórico-metodológicas têm como premissa a existência de classe social, o movimento contraditório da realidade e a produção ideológica. A classe trabalhadora (do campo e da cidade) é a que acessa a escola pública. Os conteúdos tratados na escola são determinados pela lógica curricular nacional, para a qual o campo tem lugar marginal, em especial a agricultura familiar e produção agroecológica. Esse lugar marginal tem a ver com o projeto societário em vigência no país e com o projeto de fortalecimento das atividades do agronegócio. O ideário predominante na sociedade brasileira é o de que a cidade é sinônimo de desenvolvimento e o campo é o lugar das dificuldades e precariedades. Esse ideário é construído historicamente no Brasil, embora a maior parte dos municípios seja marcada por características econômicas e socioculturais rurais, somada à baixa densidade demográfica. Para superar o ideário que define o campo como lugar de atraso é necessário conhecer experiências coletivas de trabalho na terra e de produção agroecológica, especialmente nas áreas de assentamentos da reforma agrária. A escola pública é um lugar formativo importante para 
superar ideologias e construir trabalho coletivo que possa auxiliar nos processos de transformação social. Em que pese a escola ser estatal e, em muitos casos, ser tratada como coisa particular, é nela que estuda a classe trabalhadora. Para que seja pública, a escola tem que ter o protagonismo dos seus sujeitos.

Em síntese, a orientação que nos guiou durante os trabalhos coletivos foi a de que é possível ter uma escola pública, democrática e que reconheça o campo como integrante do território brasileiro, lugar de trabalho e de diversidade sociocultural e ambiental. Trata-se de vincular a escola pública aos interesses da classe trabalhadora, seja ela do campo ou da cidade. Entretanto, a ênfase que damos ao campo se deve ao fato dele ser silenciado na maior parte dos processos formativos de professores, à exceção daqueles que foram construídos no contexto do Programa Nacional de Educação na Reforma Agrária (PRONERA) ou do Programa de Apoio à formação Superior em Licenciatura em Educação do Campo (PROCAMPO).

Trabalhamos com obras de pesquisadores que têm defendido a ideia de que é preciso "ocupar a escola pública”. Por exemplo, Martins (2009) em sua tese de doutorado defende que a ocupação da escola tem sido prática frequente nos processos educativos do MST. E, Santos (2013) em sua tese de doutorado retoma o lema do MST, do início dos anos de 1990, "Ocupar, resistir e produzir, também na educação". A pesquisadora defende que a gestão educacional do MST é democrático/participativa, com especificidades para a efetivação da pedagogia socialista. Entretanto, na maior parte das escolas públicas a gestão é formalmente a democrática. A gestão efetivamente democrática está por ser construída, pois ela depende da participação ativa de comunidades, associações de moradores, familiares, educandos, educadores e funcionários.

Neste texto, organizado em duas partes, será discutida a escola pública em relação aos princípios da Educação do Campo, em um primeiro momento. Em seguida serão indicadas ações político-pedagógicas voltadas para a transformação da escola pública no/do campo, e identificadas as disputas político-pedagógicas que se fazem presentes no movimento de interrogação da lógica da escola pública pela Educação do Campo e de resistência contra lógicas conservadoras presentes na sociedade e na escola.

\section{ESCOLA PÚBLICA E PRINCÍPIOS DA EDUCAÇÃO DO CAMPO}

A escola pública que está no campo, nas áreas que não têm atuação de movimentos sociais de trabalhadores, é marcada pela presença de entidades particulares que se inserem nas 
escolas com materiais ditos didáticos e com propostas de empreendedorismo. Também, é marcada pela presença do apostilamento do conteúdo disciplinar, na maioria das vezes, produzido por empresas. Há, também, os entes paraestatais produzindo materiais para utilização em escolas, a exemplo das Cartilhas do Programa Agrinho, do Serviço Nacional de Aprendizagem Rural (SENAR). Portanto, são escolas públicas que sofrem as determinações da política do Estado e com ela os desdobramentos da parceria público-privado.

Nas escolas há professores que possuem formação crítica e que interrogam os materiais encaminhados à escola por meio da Secretaria Municipal de Educação, resistem e criam práticas pedagógicas que valorizam o trabalho e a cultura dos povos do campo. Há, também, professores que seguem as orientações tradicionais e os materiais didáticos. A questão aqui não é criticar isoladamente a prática pedagógica, é, antes de tudo, interrogar as políticas educacionais de formação de professores - tanto a inicial com a continuada. Ainda, é necessário problematizar a política de valorização do profissional da educação e as suas condições de trabalho. Colocando os determinantes na esfera das políticas educacionais, constata-se que há muito que modificar na escola pública, em especial a que se encontra no campo. São raros os cursos de formação inicial de professores que colocam em evidência a ruralidade brasileira e as políticas educacionais em relação aos povos do campo. São vários os cursos de formação continuada que têm colocado em pauta a "Educação do Campo", entretanto, muitos deles realizados por instituições particulares de ensino que pouco ou nada conhecem do Movimento Nacional de Educação do Campo.

No conjunto dos desafios que marcam as escolas públicas rurais reside a identidade político-pedagógica. Constatamos, mediante análise documental, em particular de projetos político-pedagógicos, que a maior parte das escolas trocou a nomenclatura de "rural" para "do campo", por orientação de secretarias municipais e estaduais. Entretanto, a identidade político-pedagógica pouco ou nada foi modificada. O vínculo com os povos do campo ainda necessita ser construído para que de fato as escolas sejam do campo.

Há 20 anos, a identidade da escola do campo foi explicitada no Manifesto da I Conferência Nacional Por Uma Educação do Campo (1998). No documento está explícito que a escola do campo é aquela que mantém viva a memória dos povos, valoriza saberes e 


\section{Revista
Debates Insubmissos}

promove a expressão cultural. É o espaço de participação efetiva da comunidade que exige, luta, gere e fiscaliza as políticas educacionais. Essa escola tem o compromisso de assumir a identidade do campo e construir a referência de uma nova pedagogia. Realiza gestão democrática e está presente na vida da comunidade, assumindo, também as grandes questões e causas do campo.

Esses princípios da Educação do Campo exigem o rompimento com a lógica tradicional das escolas públicas. Trata-se de um movimento contraditório e de enfrentamentos entre concepção e projeto de sociedade e de educação. Portanto, não podemos afirmar que as escolas públicas são do campo porque elas são marcadas pela concepção da educação rural segundo a qual a instituição é determinada pelo Estado. Nesse movimento contraditório, a Educação do Campo interroga as determinações enraizadas no espaço escolar e a ideologia que vincula o campo ao projeto de modernização e de produção em larga escala para exportação. Pela lógica da educação rural as escolas devem ser fechadas para dar espaço para que as crianças acessem as escolas da cidade, consideradas com melhor infraestrutura. Pela lógica da Educação do Campo, as escolas têm que estar próximas às comunidades, vinculadas a elas e fortalecendo a identidade dos povos do campo.

Nessas duas décadas do Movimento de Educação do Campo, diversas experiências coletivas foram e estão sendo construídas nas escolas públicas, na tentativa de construir a identidade do campo. Desde programas de formação inicial de professores até programas de formação continuada, as iniciativas demonstram os potenciais para a construção de outro olhar para o campo, que conta com a participação dos povos da agricultura familiar, da pesca artesanal e das florestas. Em meio ao trabalho formativo diferenciado são muitas as disputas políticas e resistências necessárias. Uma dessas disputas refere-se ao reconhecimento dos profissionais formados pelos cursos de Licenciatura em Educação do Campo. Uma luta para construir o curso e outra luta para fazer valer a formação por áreas de conhecimento. Chegando à instituição escola, outros enfrentamentos são necessários. Um deles é fazer oposição aos materiais de entidades privadas ou paraestatais que são impostos e que nada têm a ver com a concepção de Educação do Campo construída nos movimentos sociais. Outra luta é com a construção dos projetos político-pedagógicos, que deveriam ser fruto de trabalho 


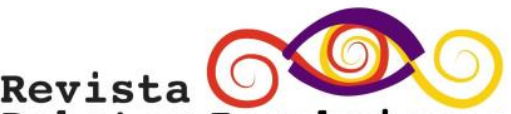 \\ Debates Insubmissos}

coletivo. Mas, muitas vezes são elaborados pela equipe pedagógica ou por assessores externos à escola, sem a participação das comunidades, funcionários, alunos e professores.

É nesse movimento de oposição, enfrentamentos e proposições que se constitui a escola do campo, com gestão democrática, vínculo estreito com os povos e fortalecimento de conhecimentos. Escola construída segundo os princípios da Educação do Campo dispostos no Decreto presidencial sob $\mathrm{n}^{\circ} 7.352$ de 4 de novembro de 2010, dentre eles: respeito à diversidade do campo; incentivo à formulação de projetos político-pedagógicos específicos para as escolas do campo; desenvolvimento de políticas de formação de profissionais da educação para o atendimento da especificidade das escolas do campo; valorização da identidade da escola do campo por meio de projetos pedagógicos com conteúdos curriculares e metodologias adequadas às reais necessidades dos alunos do campo; controle social da qualidade da educação escolar, mediante a efetiva participação da comunidade e dos movimentos sociais do campo. (BRASIL, 2010, Art. $2^{\circ}$ )

É importante ressaltar que as determinações sociais como as ações e programas governamentais interferem no processo educacional, atravancando o caminho por uma concepção de educação construída pelos próprios sujeitos do campo. No entanto, ao constatar essas contradições, necessário se faz o trabalho coletivo na luta por uma concepção de educação ligada a vida, ou seja, para a construção de uma escola vinculada à cultura e à realidade dos sujeitos, se confrontando com o sistema capitalista.

São grandes os desafios que as escolas públicas enfrentam cotidianamente num cenário marcado por determinações de um Estado conservador e que se alastra ao longo da história. Nesse sentido, as escolas públicas têm um papel fundamental de articular a materialidade da vida e reconhecer a diversidade dos povos do campo como o modo de ser, a cultura e identidade. Nesse reconhecimento é possível indagar as relações sociais, enxergar as contradições e lutar por outro projeto de sociedade baseado na justiça, igualdade e respeito pelos sujeitos.

Enfim, colocar em questão a realidade local, suas contradições, é essencial para reconhecer as formas de vida no campo e a sua oposição/ resistência/enfrentamento em relação ao avanço das atividades e práticas vinculadas/dependentes do agronegócio. (SOUZA, 2016, p. 126). 


\section{norstat 0 \\ Debates Insubmissos}

A escola é um espaço de disputas, o papel hegemônico do Estado acaba interferindo no processo educacional, pois reforça as relações capitalistas. A Educação do Campo está em constante movimento, e os sujeitos são construtores que lutam e resistem para transformar a realidade em que vivem. Esse campo de movimento está alicerçado na práxis social, na organização e na luta coletiva, na resistência por outro projeto de sociedade diante das contradições que vivenciadas a todo momento. Concordamos com Schwendler (2010, p. 23) quando afirma que "Esse campo em movimento está repleto de aprendizados, de lições da história que permitem compreender o passado, construir os enfrentamentos para recriar o próprio contexto, baseado num projeto de sociedade, de humanidade".

Caldart (2004, p. 37) nos ajuda a pensar o lugar da escola na Educação do Campo. Para ela:

Compreender o lugar da escola na Educação do Campo é compreender o tipo de ser humano que ela precisa ajudar a formar e como pode contribuir com a formação dos novos sujeitos sociais que vêm se constituindo no campo hoje. A escola precisa cumprir a sua vocação universal de ajudar no processo de humanização das pessoas com as tarefas específicas que pode assumir nesta perspectiva. Ao mesmo tempo é chamada a estar atenta à particularidade dos processos sociais do seu tempo histórico e ajudar na formação das novas gerações de trabalhadores e de militantes sociais.

Como a autora afirma, "A Educação do Campo não cabe em uma escola, mas a luta pela escola tem sido um de seus traços principais". (CALDART, 2004, p. 36). Para que a escola cumpra sua função social de "ajudar no processo de humanização das pessoas" é essencial o conhecimento e o reconhecimento dos sujeitos presentes na escola, suas histórias, memórias, trabalho, vida, cultura, além de incentivar a participação efetiva dos sujeitos no espaço escolar. A Educação do Campo é movimento da realidade marcada por contradições sociais cuja luta se constrói mediante a busca pelo bem comum e pelo processo coletivo. Caldart (2008) afirma que a Educação do Campo nasceu contra a lógica do campo como negócio, originou-se como crítica ao atual estado das coisas e na luta por direitos coletivos.

Por sua vez, como afirma Souza (2018, p.33):

A identidade das escolas públicas no/do campo deveria estar expressa nos PPPs, entretanto, o que se nota é um recorte discursivo sobre educação, currículo e avaliação. Raras vezes os documentos da Educação do Campo são mencionados nos PPPs e quando o são, parece carecer de aprofundamento e apropriação. 
Diversos estudos têm indicado que a apropriação da política da Educação do Campo não se efetivou nas escolas públicas. Trata-se de um processo em andamento como indicam Bezerra (2017) e Cruz (2014; 2018). Há uma lógica institucional enraizada nas escolas públicas e políticas educacionais que dificultam estudos e reflexões sobre o campo e a Educação do Campo, assim como há um conjunto de disputas político-pedagógicas que dificultam processos de transformação na escola.

Nesse processo de luta e disputa por uma educação crítica e problematizadora inerente à concepção da Educação do Campo, o coletivo de professores de Tijucas do Sul, com vínculo com as comunidades de agricultores familiares, vivencia a construção de outra lógica na gestão escolar e nas práticas pedagógicas, como será descrito a seguir.

\section{EXPERIÊNCIA E RESISTÊNCIA NA CONSTRUÇÃO DA ESCOLA DO CAMPO EM TIJUCAS DO SUL/PR}

O conceito de experiência e resistência nos faz lembrar a obra de Souza (2006) ao analisar a cooperação nos assentamentos organizados no MST. Para a autora:

A experiência, entendida como acúmulo de conhecimentos, possibilita a (re) elaboração de novas situações e está intrinsecamente relacionada com os saberes sociais construídos ao longo da participação no movimento social e no interior do assentamento de reforma agrária. (SOUZA, 2006, p. 33)

Nas comunidades que não estão articuladas em movimentos sociais, a experiência é sinônimo de conhecimento acumulado e de recriação das estratégias de viabilização da materialidade da vida. São experiências de produção individual e associada; convencional e agroecológica; criação de estratégias para viabilização de atividades não agrícolas entre outras.

E na escola, como se configura a experiência? São anos de repetição de práticas pedagógicas ou de criação de alternativas para que as escolas se mantenham em funcionamento quando as políticas educacionais não distinguem campo e cidade. Constrói-se uma cultura escolar da centralidade das decisões na equipe gestora. Como se forma a força de resistência? Mediante a construção de novos conhecimentos, criação de argumentos contra o 
fechamento de escolas, contra o apostilamento e empresariamento da educação, contra o distanciamento escola-comunidades e, pela construção de um projeto democrático de sociedade. Portanto, com trabalho coletivo e intencionalidade político-pedagógica voltada para a transformação.

Experiência e resistência são elementos fundantes da construção de outra lógica escolar e educacional. É como afirma Kosik (1976, p. 220): "O homem supera (transcende) originalmente a situação não com a sua consciência, as intenções e os projetos ideais, mas com a práxis [...] com o seu agir o homem inscreve significados no mundo e cria e estrutura significativa do próprio mundo". Também, como escreve Souza (2006, p. 40), "A resistência se manifesta como atitude de contestação de uma situação, como reivindicação de condições objetivas de vida [...] e a recriação de alternativas para superar determinadas condições de vida".

As pesquisas desenvolvidas no município têm permitido analisar as escolas públicas localizadas no campo, as disputas político-pedagógicas frente a projetos hegemônicos que chegam ao município. Esses projetos contrariam a concepção de Educação do Campo. Com o intuito de valorizar o contexto sociocultural dos sujeitos do campo, a comunidade escolar passou a considerar a diversidade e se autoafirmar como sujeito construtor de sua própria história, indo em busca de uma nova concepção de educação. Conforme afirma Freire (2003, p.21) "o profissional deve ir ampliando seu conhecimento em torno do homem, de sua forma de estar sendo no mundo, substituindo por uma visão crítica a visão ingênua da realidade, deformada pelos especialismos estreitos". Significa superar a visão ideológica dominante que têm diminuído a cultura e o trabalho dos povos que vivem no campo e os têm despojados de seus direitos sociais.

Nesse sentido, constatam-se mudanças nas práticas dos professores com relação à valorização da cultura e identidade local, antes não percebida. Cultura como práxis está envolta de experiência e resistência. É como escreve Schelling (1990, p. 36-37): “a produção cultural da sociedade está intimamente vinculada às relações de poder econômico, político e ideológico na vida social entre grupos, classes, nações e civilizações dominantes e subordinados". 
Por meio dos estudos e encontros com a comunidade escolar, novas formas de perceber o campo foram se construindo. Partindo da identidade das comunidades e do contexto sociocultural dos sujeitos foi possível refletir sobre a realidade e delinear caminhos, redimensionando as práticas antes individualizadas. Nessa direção, caminha-se de um estado "passivo", para outro estado "ativo".

No contexto da pesquisa colaborativa, que envolveu os professores das escolas municipais de Tijucas do Sul, duas perguntas fora orientadoras, a saber: "Que escola temos? Que escola queremos"?. A procedência dos debates foi gerando provocações no coletivo e as pessoas passaram a perceber as contradições, aos poucos o coletivo foi construindo um projeto político-pedagógico alicerçado na formação humana. Assumir essa condição de sujeito da própria história é redimensionar os processos educativos, como protagonistas por uma nova construção social.

No decorrer do trabalho coletivo no município, foi desenvolvido um curso de Especialização em Educação que contou com 14 trabalhos de conclusão elaborados por professores do município, todos versando sobre escola e Educação do Campo. Foram trabalhos resultantes de investigação nas próprias escolas de trabalho dos professores-autores. Os temas analisados indicam os problemas que preocupam os professores nas escolas localizadas no campo e ficaram expressos seguintes títulos dos textos: 1) Dislexia nas escolas do campo. 2) Práticas discriminatórias: por meio de representações simbólicas na Educação do Campo. 3) Biblioteca Escolar e a Realidade das Escolas do Campo do Município de Tijucas do Sul: Desafios do acesso. 4) Comunidade Barreiro de Tijucas Do Sul: Um estudo de caso. 5) As políticas públicas e os desafios da formação continuada do professor alfabetizador da escola do campo. 6) Estudo de caso: O trabalho Pedagógico na Escola localizada no campo municipal Senador alô Guimarães. 7) Os diversos usos da química no cotidiano: processos de ensino e aprendizagens para Educação do Campo. 8) A contribuição do ensino de Geografia à Educação do Campo. 9) Comunidade Faxinalense de Postinho: Uma história de amor e luta pela preservação de suas tradições. 10) A Ludicidade na prática pedagógica nas escolas localizadas no campo. 11) Contextualizando a Educação do Campo: trajetória, conquistas e desafios. 12) Organizações Sociais em Tijucas do Sul. 13) O Desenvolvimento das aulas de 
arte nos anos iniciais. 14) O ensino da Geografia nas escolas do Campo do Município de Tijucas do Sul.

O curso de especialização, realizado no período de 2013 a 2016, foi importante para consolidar os estudos da Educação do Campo e, especialmente, para fortalecer a ideia de que o município é rural e de que a escola pode contribuir para o fortalecimento da identidade do campo e dos povos do campo, bem como lutar por políticas educacionais que estejam ao encontro das necessidades dos trabalhadores.

O curso e esses trabalhos de investigação nas escolas fortaleceram o debate da Educação do Campo no município, o que propiciou a organização do I Seminário Intermunicipal sediado em Tijucas do Sul. Esse seminário contou com oficinas que problematizaram em torno de 15 eixos temáticos que interessam ao fortalecimento da Educação do Campo. Alguns desses eixos foram: identidade da escola do campo; formação de professores; materiais didático-pedagógicos; escolas multisseriadas e processo de aprendizagem; educação ambiental no contexto da Educação do Campo; relação escolacomunidade; projeto político-pedagógico; avaliação do ensino-aprendizagem; trabalho e educação; educação especial no contexto da Educação do Campo entre outros.

Foi dessa forma que houve identificação do pertencimento a uma identidade negada aos sujeitos do campo, passando, então, para o estágio da luta por outro projeto de sociedade. Os sujeitos fizeram-se protagonistas e não meros expectadores recebendo determinações do Estado e do sistema capitalista. Nas palavras de Paulo Freire (1996, p. 54) “Afinal, minha presença no mundo não é a de quem a ele se adapta, mas a de quem nele se insere. $E$ $a$ posição de quem luta para não ser apenas objeto, mas sujeito também $d a$ história”.

Nessa direção, Souza (2008, p. 1109) afirma que “A construção da Educação do Campo vem sendo marcada por uma prática social que indaga a educação pública estatal e que demanda/fortalece a educação pública proveniente das reflexões dos povos do campo".

Aos poucos, o coletivo constatou que para construir uma escola do campo é preciso superar os diferentes projetos de sociedade existentes. Esses projetos com ideários ligados ao capital contrariam a formação humana. Importante a ideia de Caldart $(2004$, p. 20$)$ de que "A Educação do Campo nasceu colada ao trabalho e à cultura do campo. E não pode perder isso 
em seu projeto". Ainda, afirma que "A leitura dos processos produtivos e dos processos culturais formadores (ou deformadores) dos sujeitos do campo é tarefa fundamental da construção do projeto político e pedagógico da Educação do Campo”.

As disputas político-pedagógicas em torno das escolas públicas podem ser evidenciadas quando determinantes externos obstaculizam o movimento de construção de um projeto ligado a formação humana dos sujeitos. Ao construirmos um novo projeto baseado na formação humana, passamos a pertencer e reconhecer a nossa própria história, uma história de luta, de intencionalidade política e pedagógica, uma história de compromisso coletivo.

O movimento contraditório na construção da Educação e da escola do campo é marcado por disputas assim configuradas: 1) Uma concepção de educação voltada aos interesses da classe trabalhadora se contrapondo a uma concepção de educação nos moldes tradicionais e burocráticos; 2) Uma concepção de educação de campo, articulando o modo de vida, a cultura e identidade dos sujeitos do campo, se contrapondo a uma educação distante da especificidade do campo, ou seja, uma educação baseada na concepção rural; 3) Disputa por projetos societários ligados a produção de vida se contrapondo com a relação mercadológica; 4) Disputas por territórios, como a luta pela agricultura familiar e a contraposição ao agronegócio. 5) Disputas por conteúdos relacionados à especificidade dos sujeitos do campo, respeitando o seu contexto sociocultural, se contrapondo com conteúdos mecânicos, lineares, determinados e sem criticidade. 6) Uma formação de professores condizente com a especificidade das escolas do campo se contrapondo a uma concepção de educação empreendedora, do agronegócio, da meritocracia. 7) A participação coletiva dos sujeitos por meio de uma gestão democrática se contrapondo a uma gestão dominadora, autoritária e clientelista.

No trabalho colaborativo foi possível mapear as ações impostas às escolas que têm aderência à educação rural e à concepção de campo do agronegócio e ao empresariamento da educação, a saber: 1) Programa Agrinho no Município cuja concepção distancia-se dos princípios da Educação do Campo; 2) Projeto Comfloresta que se contrapõe com a formação humana dos sujeitos, pois fortalece o agronegócio, a exploração dos trabalhadores, o desmatamento, a extinção dos animais; 3) O SEBRAE (Serviço Brasileiro de Apoio às Micro 
e Pequenas Empresas), programa ligado ao agronegócio e ao empreendedorismo; 4) Sistema Aprende Brasil, cujo material proporciona a privatização de ensino, o qual impactou no movimento coletivo dos professores contrários ao apostilamento dos conteúdos escolares e às determinações empresariais na esfera educacional.

Cabe destacar que esses programas contrariam a concepção de educação articulada à classe trabalhadora. A luta coletiva é por uma escola que seja constituída pela colaboração dos sujeitos, pelas trocas de experiências coletivas, uma escola pública que caminhe diante de uma metodologia que integre as disciplinas e que problematize, faça o educando pensar para transformar. O coletivo resiste contra a meritocracia, a individualidade, a competitividade e os direitos negados aos povos do campo. A comunidade escolar, com conhecimento dos princípios da Educação do Campo, começa a indagar projetos que chegam às escolas. Há resistência por parte de um coletivo, negação dos professores em trabalhar com esses programas, em especial, o Sistema Aprende Brasil, implantado sem consulta da comunidade escolar no ano de 2017.

Nessa caminhada de construção da Educação do Campo evidenciamos o movimento dos professores que se colocam como protagonistas, não aceitando receber "pacotes prontos" e distantes da realidade do campo. Martins (2009, p. 33), em sua tese intitulada "Ocupação da Escola: uma categoria em construção”, enfatiza que é possível evidenciar a manifestação da ocupação da escola na história da educação por meio de ações educacionais concretas. Ressalta que "construir a ocupação da escola é compreender a educação capitalista e o Estado onde ela está inserida e ir além". Nesse sentido, o autor afirma que "A escola é um espaço de disputa hegemônica". Se "ocupada" pelos sujeitos sociais que a compõem, a classe trabalhadora é uma agência capaz de atuar como "elemento estatal" na contracorrente do Estado. Dessa forma, a comunidade escolar luta por essa ocupação da escola, desafiando o modo de produção capitalista.

No movimento de luta e disputa, analisamos a conjuntura política e constatamos que houve mudanças na troca de gestão municipal. A nova gestão (2017) traz a ideologia vinculada à concepção de educação rural, ignorando os debates realizados nos anos anteriores. De 2017 para cá há uma conjuntura política que se mostra distanciada de um projeto de 
sociedade da classe trabalhadora. Uma conjuntura difícil, tanto na esfera estadual, como na federal e na municipal.

A política de formação continuada, no que se refere à concepção da Educação do Campo, foi realizada no município no período de 2011 a 2016. Era uma conjuntura favorável à Educação do Campo. No entanto, em 2017, com a nova conjuntura política, as discussões e grupos de estudos da Educação do Campo estão limitados. Porém, com o apoio do Conselho Municipal de Educação tem havido contraposição a programas ligados ao agronegócio, ao empreendedorismo, a privatização de ensino.

Nesse mundo contraditório, não podemos perder a força entre coletivos, ultrapassando barreiras, resistindo a um sistema que oprime e ignora a classe trabalhadora. Paulo Freire está tão presente em nossos dias, e a Pedagogia do Oprimido nos faz refletir sobre esses momentos contraditórios. De um lado a classe oprimida e de outro a classe opressora. Mas, "A partir do momento em que um coletivo problematiza as questões da sua realidade, se inquieta diante dela percebendo as contradições existentes na sociedade, inicia-se um processo de conscientização política”. (CRUZ, 2014, p.201).

Foi dessa forma que as disputas foram acontecendo na escola e na comunidade, as pessoas começaram a refletir e a problematizar as contradições vividas e iniciou-se um processo de luta e resistência diante de diferentes concepções de educação. Como afirma Souza (2016, p. 134): “Ao problematizar a escola pública, pensando políticas e práticas, a intenção é reforçar ações que têm aproximação com a concepção da Educação do Campo e reconhecer as práticas da educação rural que necessitam de superação".

Nesse processo de superação houve a extinção dos programas e projetos como: Programa Agrinho, extinção do SEBRAE, Projeto Comfloresta, resistência ao Sistema ${ }^{3}$ Aprende Brasil. Cabe ressaltar que a implantação do Sistema Aprende Brasil, em 2017, foi contestada pelos professores e comunidade que não aceitavam a imposição desse material,

\footnotetext{
${ }^{3}$ É um Sistema de Ensino organizado pela Editora Positivo. Oferece um conjunto específico de soluções para a rede de ensino pública: Livro Didático Integrado, também em versão digital, com assessoria pedagógica e plataforma virtual de aprendizagem. Disponível em http://www.editorapositivo.com.br/sistemas-deensino/aprende-brasill. Acesso em: 6 out. 2018.
} 
que não correspondia com o contexto do campo. Os professores organizaram cartas de repúdio e foram até a câmara de vereadores questionar o ensino por apostilamento, além de debater a identidade dos povos do campo e a implantação do material sem consulta à comunidade escolar.

Essa manifestação coletiva gerou a instauração da CPI (Comissão Parlamentar de Inquérito) pela Câmara de vereadores em parceria com o Conselho Municipal de Educação. Após a análise dessa comissão, ouvindo professores, pais de alunos, Presidente do Conselho Municipal de Educação, constatou-se a rejeição desse material. Em 2018 o sistema de apostilamento foi extinto do município. Após a extinção do material Positivo, os professores iniciaram a elaboração de um material próprio sobre o município de Tijucas do Sul, com temáticas voltadas à identidade dos sujeitos.

Na trajetória construída, entre luta e disputa, predomina a resistência e a esperança de dias melhores, por uma concepção de educação digna e uma escola pública que supere a lógica capitalista. A construção de uma nova ordem social é um processo e sempre estará em movimento. Nosso desafio é continuar nesse movimento de luta coletiva, ultrapassando as barreiras, sem desanimar diante das contradições vividas.

Concordando com Souza (2018, p. 32), transcrevemos o que segue:

\begin{abstract}
O trabalho com a pedagogia crítica gera "desconforto" entre profissionais que não tiveram formação em Educação do Campo, pois coloca em xeque as verdades construídas e pautadas no Positivismo como concepção filosófica de mundo e de educação. A construção de outras verdades exige esforço, estudo, disposição e trabalho coletivo. Os professores das escolas públicas, em sua maioria, desejam estudar, entretanto estão "presos" às lógicas institucionais de rotinas, horários, disciplinas e permanência em mais de uma escola durante a jornada de trabalho. Assim, a política educacional de "desvalorização" do profissional docente é um entrave para o avanço de processos de superação de ideologias e de práticas estruturadas a partir do pensamento fragmentário e pautado no senso comum.
\end{abstract}

De certa maneira, o que tem sido feito no município de Tijucas do Sul é a construção da pedagogia crítica mediante o trabalho coletivo. Entretanto, esse é um processo marcado por contradição que se evidencia nas conjunturas políticas. Um governo democrático propicia o avanço de relações democráticas e fortalece o trabalho coletivo na educação. Um governo centralizado em ações clientelistas reforça relações autoritárias e enfraquece a perspectiva crítica. Portanto, a conjuntura política é uma determinação importante na construção da 
política de Educação do Campo, especialmente, em municípios cuja população não está organizada em movimentos sociais de trabalhadores. Mas, a relação de forças está estabelecida no campo democrático e a resistência será maior por parte da classe trabalhadora quanto maior for a organização e a consciência política.

A construção de um projeto democrático e construído pela classe trabalhadora é desafiador. Ultrapassar os limites e entraves diante de uma sociedade capitalista requer resistência no enfrentamento das disputas políticas e pedagógicas em torno das escolas públicas. Disputam-se, de um lado, o projeto neoliberal e, de outro lado, o projeto democrático e participativo.

Segundo Dagnino (2005, p. 5):

[...] o projeto neoliberal encontra no Brasil um contendor relativamente consolidado, embora evidentemente não hegemônico, capaz de constituir um campo de disputa. A existência desse contendor e dessa disputa determina, na nossa perspectiva, direções específicas às estratégias e formas de atuação das forças vinculadas ao projeto neoliberal em nosso país que, se não se afastam das direções adotadas no nível global, adquirem especificidade própria na medida em que são forçadas a estabelecer relações de sentido e um terreno de interlocução com o campo adversário. A necessidade dessa interlocução se acentua no interior dos espaços públicos de participação do Estado e da sociedade civil quando se defrontam face a face esses dois projetos.

A autora indica que há uma crise discursiva diante de uma confluência perversa, de um lado o projeto neoliberal que se estabelece em nosso país nos últimos anos e de outro lado o projeto democratizante e participativo, que surge por meio das crises do regime autoritário. A autora define perversa como um fenômeno que se opõe a aparência e que os efeitos não são imediatamente evidenciados. Destarte, esses projetos são antagônicos e há uma disputa tensa que se caracteriza por crenças e interesses que se ajustam para a ação política dos diferentes sujeitos.

Enfim, muitas experiências foram realizadas no município desde 2011, a saber: Reestruturação de projetos político-pedagógicos, seminários municipais e intermunicipais de Educação do Campo, construção de um livro coletivo "Meu Município, minha Cultura", formações de professores articuladas ao contexto do campo, debates intermunicipais com professores que atuam com classes multisseriadas, inclusão da Educação do Campo e Educação Ambiental no Plano Municipal de Educação, estudos coletivos de professores na 
reformulação do currículo, incluindo a diversidade do campo, constituição de eleição de diretores nas escolas, organização dos conselhos escolares nas instituições de ensino.

A escola pública, enquanto uma instituição do Estado, não pode se reduzir a concepção patrimonialista do Estado, pois nela há vida, há pensamento, há diversidade cultural, enfim, há gente em movimento.

\section{CONSIDERAÇÕES FINAIS}

Diante da análise da escola pública tomando como referência os princípios da Educação do Campo, destacamos experiências de resistência à concepção hegemônica de sociedade e de educação. O objetivo foi expor experiência e resistência como prática social voltada para a transformação de políticas e práticas pedagógicas. E, mostrar que é possível a apropriação da política de Educação do Campo nas escolas públicas que não estão em áreas de assentamentos e de acampamentos da reforma agrária.

Sendo assim, as ideias centrais defendidas ao longo do texto foram: 1) ponto de partida para a ação colaborativa nas escolas públicas é o conhecimento dos documentos construídos no Movimento Nacional de Educação do Campo, sejam eles oficiais como diretrizes curriculares ou produção bibliográfica de coletivos de pesquisadores. Esse conhecimento possibilita a interrogação de práticas e políticas enraizadas na escola pública e abre espaço para a criação de novas frentes de trabalho pedagógico e de fortalecimento da identidade da escola do campo. 2) articulação dos professores com as comunidades locais a fim de identificar características socioculturais, tipo de relação de trabalho e de vínculo com a terra. Ou seja, identificar coletivamente as marcas da ruralidade municipal é fundamental para a consolidação da identidade da escola do campo. 3) reestruturação dos projetos políticopedagógicos de cada escola mediante participação dos sujeitos envolvidos na escola pública. Assim, exercita-se participação e reconhecimento dos povos do campo por eles mesmos em conjunto com os professores, muitos também moradores do campo. 4) fortalecimento da formação continuada com a formação de grupos de estudos que direcionaram o olhar para a própria realidade. Embora durante a pesquisa colaborativa não tivéssemos trabalhado com os complexos de estudo e inventário da realidade, consideramos que as experiências já 
construídas no estado do Paraná têm na sua essência sujeitos com formação política, formação teórica e técnica fundamentada em outro projeto de sociedade, fundado na pedagogia socialista. No estado, existem municípios com assentamentos rurais que trabalham coletivamente a terra, comunidades de assentados que se pautam pelos princípios da agricultura agroecológica, escolas com experiência no trabalho pedagógico baseado no inventário da realidade, nos ciclos de formação humana e nos complexos de estudo (SAPELLI, 2017). São experiências essenciais para a transformação social, construídas em meio a contradição, disputa política e violência. 5) realização de seminários articulados com outros municípios da Região Metropolitana de Curitiba. Seminários que reuniram de 200 a 600 professores das escolas públicas do campo e da cidade, em debates sobre escola, campo, políticas públicas e práticas pedagógicas. 6) realização de um curso de especialização em Educação do Campo que auxiliou no fortalecimento das experiências pedagógicas centradas na Educação do Campo. 7) envolvimento em manifestações sociais locais contrárias à presença de apostilas do Sistema Positivo no município e participação no espaço do poder legislativo para garantir a discussão da Educação do Campo e da educação ambiental no município.

Em síntese, são ações coletivas que levaram a interrogações sobre a escola pública, sua organização e vínculo com os povos do campo. Fortaleceram o município no que diz respeito ao reconhecimento das comunidades, do trabalho no campo e da escola. Entretanto, a continuidade do trabalho coletivo guarda relação com a conjuntura política e com o projeto de educação defendido na esfera municipal. Os professores estão fortalecidos como sujeitos da própria prática, entretanto, a vigilância política é permanente, em especial por conta das disputas em torno da concepção de Educação do Campo que se manifestam nacionalmente.

Finalizamos este texto num momento de incertezas para o país e para a educação brasileira. Apostamos na predominância da democracia e da liberdade de expressão das ideias. Defendemos a retomada de projetos societários que valorizam a formação, a educação e a escola pública. 


\section{REFERÊNCIAS}

ARROYO, M. G. As matrizes pedagógicas da Educação do Campo na perspectiva da luta de classes. In: MIRANDA, S. G.; SCHWENDLER, S. F. Educação do Campo em movimento: teoria e prática cotidiana. V. I. Curitiba: Editora da UFPR, 2010. P. 35-54.

BEZERRA, Delma Rosa dos Santos. O processo de apropriação da política da Educação do Campo por profissionais de uma escola no interior do estado de São Paulo. 249 fls. Tese (Doutorado em Psicologia), Universidade de São Paulo, Ribeirão Preto, 2017.

BRASIL. Ministério da Educação. Resolução CNE/CEB no 1, de 3 de abril de 2002. Institui Diretrizes Operacionais para a Educação Básica das Escolas do Campo. Diário Oficial da União, Brasília, DF, 9 abr. 2002.

BRASIL. Ministério da Educação. Resolução CNE/CEB no 2, de 28 de abril de 2008. Estabelece diretrizes complementares, normas e princípios para o desenvolvimento de políticas públicas de atendimento da Educação Básica do Campo. Diário Oficial da União, 29/4/2008, Seção 1, p. 25-26.

BRASIL. Decreto no 7.352 , de 4 de novembro de 2010. Dispõe sobre a política de Educação do Campo e o Programa Nacional de Educação na Reforma Agrária - PRONERA. Diário Oficial da União, Brasília, DF, 5 nov. 2010.

BRASIL. Lei $n^{\circ} 12.960$ de março de 2014. Altera a Lei no 9.394, de 20 de dezembro de 1996, que estabelece as diretrizes e bases da educação nacional, para fazer constar a exigência de manifestação de órgão normativo do sistema de ensino para o fechamento de escolas do campo, indígenas e quilombolas. Diário Oficial da União, Brasília, DF, 28 de mar. 2014.

CALDART, Roseli Salete. Elementos para construção do Projeto Político-Pedagógico da Educação do Campo. In: MOLINA, Mônica Castagna; JESUS, Sônia Meire Azevedo de (Orgs.). Por Uma Educação do Campo: Contribuições para um projeto de Educação do Campo. Brasília, DF: Articulação Nacional "Por Uma Educação do Campo", 2004. Coleção Por Uma Educação do Campo, nº 5. p. 10 - 31.

CALDART, Roseli Salete. Sobre Educação do Campo. In: SANTOS, Clarice Aparecida dos. (Org.). Por uma Educação do Campo: campo-políticas públicas-Educação. Brasília: INCRA; MDA, 2008.

CALDART, Roseli Salete. Educação do Campo: notas para uma análise de percurso. Trabalho, Educação e Saúde, v. 7, n 1, p. 35-64, mar/jun. Rio de Janeiro, 2009.

CNEC. CONFERÊNCIA POR UMA EDUCAÇÃO BÁSICA DO CAMPO. Compromissos e desafios. Luziânia, 27 a 31 de julho de 1998. 
CRUZ, Rosana Aparecida da. Reestruturação do projeto político-pedagógico das escolas municipais localizadas no campo no Município de Tijucas do Sul. 229fls. Dissertação (Mestrado em Educação), Universidade Tuiuti do Paraná, Curitiba, 2014.

CRUZ, Rosana Aparecida da. Educação e contradição: disputas político-pedagógicas em torno da escola pública do campo. 213 fls. Tese (Doutorado em Educação), Universidade Tuiuti do Paraná, Curitiba, 2018.

DAGNINO, Evelina. Políticas culturais, democracia e o projeto liberal. Dossiê Nacional, Revista Rio de Janeiro, n. 15, jan. - abr. 2005. Disponível em: http://www.forumrio.uerj.br/ documentos/revista_15/15_dossie_EvelinaDagnino.pdf. Acesso: 14 out. 2018.

FERNANDES, Bernardo Mançano. Diretrizes de uma caminhada. In: ARROYO, Miguel Gonzáles; CALDART, Roseli Salete; MOLINA, Mônica Castagna (Orgs.). Por Uma Educação do Campo. Petrópolis: Vozes, 2004. P. 133-145.

FERNANDES, Bernardo Mançano. Território camponês. In: Caldart et al. Dicionário da Educação do Campo. Rio de Janeiro, São Paulo: Escola Politécnica de Saúde Joaquim Venâncio, Expressão Popular, 2012.

FREIRE, Paulo. Pedagogia da Autonomia: Saberes Necessários à Prática Educativa. São Paulo: Paz e Terra, 1996.

FREIRE, Paulo. Educação e mudança. 12. ed. São Paulo: Paz e Terra, 2003.

FREIRE, Paulo. Pedagogia do Oprimido. 17. Ed. Rio de Janeiro: Paz e Terra, 1987.

IPARDES. Instituto Paranaense de Desenvolvimento Econômico e Social. Caderno Estatístico Município de Tijucas do Sul, 2017. Disponível em: $<$ http://www.ipardes.gov.br/cadernos/MontaCadPdf1.php?Municipio=83190>. Acesso: 28 set. 2018.

KOSIK, Karel. Dialético do concreto. São Paulo: Paz e Terra, 1976.

MACHADO, Rita das Dores. A cultura como matriz pedagógica na proposta curricular das escolas localizadas no campo. 144fls. Dissertação (Mestrado em Educação). Universidade Tuiuti do Paraná. Curitiba, 2016.

MARTINS, Fernando José. Ocupação da Escola: uma categoria em construção. 282 f. Tese (Doutorado em Educação) - Universidade Federal do Rio Grande do Sul. Faculdade de Educação. Programa de Pós-Graduação em Educação. Porto Alegre, 2009. 
MOLINA, Mônica Castagna; SÁ, Laís Mourão. Escola do Campo. In: CALDART, Roseli Salete et al. (Org.) Dicionário da Educação do Campo. Rio de Janeiro: IESJV, Fiocruz; São Paulo: Expressão Popular, 2012.

MUNARIM, Antônio. Movimento Nacional de Educação do Campo: uma trajetória em

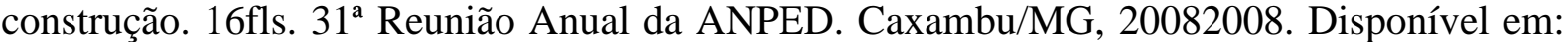
$<$ http://www.anped.org.br/reunioes/31 ra/1trabalho/GT03-4244--Int.pdf>. Acesso: 20 set. 2018.

MUNARIM, Antônio; BELTRAME, Sonia Aparecida Branco; CONDE, Soraya. Franzoni; PEIXER, Zilma. Educação do Campo: reflexões e perspectivas. Florianópolis: Insular, 2010.

MUNARIM, Antônio. Educação do Campo e políticas públicas: controvérsias teóricas e políticas. In: MUNARIM, Antônio; BELTRAME, Sônia; CONDE, Soraya Franzoni; PEIXER, Zilma Izabel. (Orgs.). Educação do Campo: políticas públicas, territorialidades e práticas pedagógicas. Florianópolis: Insular, 2011. (p. 21 - 38).

PARANÁ. Secretaria de Estado da Educação. Diretrizes Curriculares da Educação do Campo. SEED: Curitiba, 2006. Disponível em: <http://www.educadores.diaadia.pr.gov.br/ arquivos/File/diretrizes/diretriz_edcampo.pdf> Acesso: 14 out. 2018.

RIBEIRO, Marlene. Educação do Campo: embate entre Movimento Camponês e Estado. Educ. Rev.. Belo Horizonte, 2012, vol.28, n.1, pp. 459-490

SANTOS, Arlete Ramos dos. "Ocupar, resistir e produzir, também na educação!” o MST e a burocracia estatal: negação e consenso. 395 fls. Tese (Doutorado em Educação), Universidade Federal de Minas Gerais, Belo Horizonte, 2013.

SAPELLI, Marlene Lucia Siebert. Ciclos de formação humana com complexo de estudos nas escolas itinerantes do Paraná. Educ. Soc., Campinas, v. 38, nº 140, p. 611-629, jul-set, 2017. Disponível em http://www.scielo.br/pdf/es/v38n140/1678-4626-es-38-140-00611.pdf Acesso: 15 de jul. 2018.

SCHELLING, Vivian. A presença do povo na cultura brasileira. Campinas: Editora da UNICAMP, 1990.

SCHWENDLER, Fátima Sônia. Uma Introdução à Educação do Campo em Movimento. In: MIRANDA, Sônia Guariza. (Orgs.). Educação do Campo em Movimento. Teoria e Prática Cotidiana - v.1. Curitiba: UFPR, 2010. p. 23-32.

SOUZA, Maria Antônia de. Educação e cooperação nos assentamentos do MST. Ponta Grossa: Editora da UEPG, 2006. 
SOUZA, Maria Antônia de. Educação do Campo: políticas, práticas pedagógicas e produção científica. Educ. Soc., Campinas, v. 29, n. 105, p. 1089-1111, set./dez. 2008. Disponível em <http://www.cedes.unicamp.br>. Acesso em: 28 set. 2018.

SOUZA, Maria Antônia de. A educação é do campo no estado do Paraná? In: SOUZA, Maria Antônia de (org.). Práticas educativas no/ do campo. Ponta Grossa: Editora da UEPG, 2011.

SOUZA, Maria Antônia de. Educação do Campo: desafios para as escolas públicas. In: WIZNIEWSKY, Carmen Rejane Flores; MOURAD, Leonice Aparecida de Fátima Alves. (Orgs.). Educação, memória e resistência popular na formação social da América Latina. Porto Alegre: Evangraf, 2016. p. 111-136.

SOUZA, Maria Antônia de. Educação do Campo, escola pública e projeto políticopedagógico. In: SOUZA, Maria Antônia de (org.). Escola pública, Educação do Campo e projeto político pedagógico. Curitiba: Editora da UTP, 2018. P. 17 - 40.

Submetido em: 15/10/2018

Aprovado em: 08/12/2018 